\title{
Identifikasi Kerusakan dan Rekomendasi Perbaikan Embung Kecil di Kota Kupang, Provinsi Nusa Tenggara Timur
}

\author{
Oktovianus Edvict Semiun ${ }^{1}$ \\ ${ }^{1}$ Universitas Katolik Widya Mandira, Kupang
}

\begin{abstract}
Article History ABSTRACT
Received 16.07.2019

Received in revised form 22.09.2019

Accepted 05.10.2019

Available online 28.10.2019

IDENTIFICATION OF DAMAGE AND RECOMMENDATION OF SMALL FARM WATER RESERVOIR IMPROVEMENT IN KUPANG CITY, NUSA TENGGARA TIMUR PROVINCE. The condition of small farm water reservoir that exist today in Kupang has faced a lof of the decrease of service levels due to the effective age factor, sedimentation factor, effectiveness and the damage construction factor. This can eventually interfere the demand for water needs of people in Kupang. Therefore, the existence of facilities and infrastructure of water resources, especially permanent small farm water reservoir in particular, is absolutely necessary and to be maintained. Generally, the problem of small farm water reservoir is a functional degradation characterized by the reduction of capacity of accommodated water, sedimentation, blogging, a wild plantin the body of the weir or embankment, erosion, and some other problems. In order to overcome the problem of fulfillmentof water needs that continue to increase in various purposes, it is necessary to return the function of supply of water resources especially farm water reservoir and optimize the development of water resources potentials in accordance with the priority and ability of existing funds. The purpose of this community service are to identify the existing condition building and to compiled a review of damage identification results and recommend the repairmen of small farm water reservoir.
\end{abstract}

KEYWORDS: Community Service, Kupang City, Small Farm Water Reservoir.

DOI: 10.30653/002.201943.172

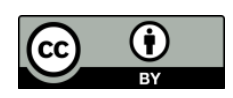

This is an open access article distributed under the terms of the Creative Commons Attribution 4.0 International License, which permits unrestricted use, distribution, and reproduction in any medium, provided the original work is properly cited. ๑ 2019 Oktovianus Edvict Semiun.

\section{PENDAHULUAN}

Provinsi Nusa Tenggara Timur (NTT) merupakan bumi Indonesia bagian timur yang menganggap air sebagai sumber kehidupan bagi bumi yang gersang dan rakyat yang miskin di bumi nusantara. Sebagai provinsi kepulauan (566 pulau dengan hunian hanya pada 42 pulau) setelah Maluku, NTT dihadapkan pada kenyataan resource

\footnotetext{
${ }^{1}$ Corresponding author: Program Studi Teknik Sipil, Fakultas Teknik Universitas Katolik Widya Mandira; Jl. San Juan, Penfui, Kupang,
} Nusa Tenggara Timur; Email: oktovianusedvict@gmail.com 
endowment yang kurang subur, sempit, berbatu dan beriklim kering (Notoatmojo dan Rivai, 2001). Salah satunya yaitu kota Kupang.

Kota Kupang merupakan ibukota provinsi NTT yang memiliki luas 180,27 km² terdiri dari 6 Kecamatan. Kecamatan yang terluas adalah Kecamatan Alak dengan luas $86,91 \mathrm{~km}^{2}$ sedangkan kecamatan dengan luas wilayah terkecil adalah Kecamatan Kota Lama yaitu sebesar 3,22 km² (Badan Pusat Statistik Kota Kupang, 2018).

Iklim yang tidak menentu di Kota Kupang merupakan masalah umum. Dalam setahun musim kemarau relatif lebih panjang dari pada musim penghujan. Pada tahun 2017 temperatur udara terendah adalah $22,4^{\circ} \mathrm{C}$ yang terjadi pada bulan September sedangkan temperatur tertinggi adalah $33,5^{\circ} \mathrm{C}$ pada bulan Agustus. Curah hujan tertinggi adalah $446 \mathrm{~mm}$ pada bulan Januari dengan jumlah hari hujan sebanyak 20 hari (Badan Pusat Statistik Kota Kupang, 2018).

Sebagian besar wilayah kota Kupang mempunyai kondisi topografi berbukit-bukit dan banyak cekungan yang dapat menampung air hujan. Berdasarkan kondisi tersebut dan potensi limpasan air permukaan yang besar pada musim hujan, maka salah satu upaya penyediaan sumber air untuk penyediaan air irigasi, air baku untuk manusia dan ternak adalah memanfaatkan air permukaan dengan membangun embung-embung sebagai wadah penampungan air pada musim hujan yang dapat dimanfaatkan pada musim kemarau (Sutapa, 2008). Menurut Puspitaningrum dalam Hanggara dan Irvani (2019), teknologi embung merupakan salah satu teknologi untuk konservasi air terutama solusi/pemecahan masalah kekeringan. Hal ini juga didukung oleh penelitian yang dilakukan Notoatmojo dan Rivai (2001) yang menegaskan bahwa pemanfaatan embung untuk air minum dan kebun akan lebih meningkatkan pendapatan, kesejahteraan penduduk, serta keberlanjutan (sustainability) embung.

Embung merupakan waduk berukuran mikro di lahan pertanian (small farm reservoir) yang memiliki multifungsi serta dibangun untuk digunakan sebagai pengendali kelebihan air ketika musim penghujan dan menjadi sumber air irigasi pada musim kemarau. Secara operasional sebenarnya embung berfungsi untuk mendistribusikan dan menjamin kontinuitas ketersediaan pasokan air untuk keperluan tanaman ataupun ternak di musim kemarau dan penghujan (Asdak, 1995; Nirwana, 2016). Sedangkan embung kecil adalah bangunan yang berfungsi menyimpan air di musim hujan yang dimanfaatkan oleh suatu desa, hanya selama musim kemarau untuk memenuhi kebutuhan prioritas penduduk, ternak dan sedikit kebun (hanya terbatas pada kebutuhan yang lebih kecil). Bangunan ini biasanya dibangun pada daerah-daerah kritis air. Artinya pada musim penghujan daerah tersebut kebanjiran namun pada musim kemarau airnya sangat sedikit hingga kering (Subarkah, 1990).

Kondisi embung yang ada saat ini di kota Kupang sudah banyak mengalami penurunan tingkat pelayanan baik karena usia umur efektifnya, faktor sedimentasi maupun kerusakan konstruksi. Hal ini pada akhirnya akan mengganggu pemenuhan kebutuhan air di masyarakat. Oleh karena itu, keberadaan sarana dan prasarana sumber daya air (SDA) khususnya embung mutlak diperlukan dan tetap dipertahankan tingkat keandalannya. Permasalahan embung (small farm water reservoir) pada umumnya adalah degradasi fungsional, ditandai dengan berkurangnya kapasitas air tertampung, sedimentasi, rembesan, tumbuhnya tanaman liar pada tubuh bendung/tanggul, erosi, dan beberapa masalah lainnya (Kasiro, 1995). 
Pemerintah pusat dan daerah sejak tahun 1990 sudah mengembangkan usaha embung di daerah NTT untuk pengadaan air minum dan irigasi (Notoatmojo dan Rivai, 2001). Namun embung-embung tersebut mengalami penurunan kelayakan aspek teknisnya sebagai akibat dari kerusakan yang terjadi. Untuk mengatasi masalah pemenuhan kebutuhan air yang terus meningkat di berbagai keperluan, maka perlu mengembalikan fungsi kondisi sarana dan prasarana SDA khususnya sarana/prasarana embung dan mengoptimalkan pengembangan potensi sumber daya air secara bertahap sesuai prioritas dan kemampuan dana yang ada. Namun sering kali kendala yang dihadapi adalah kurangnya informasi dan database tentang tingkat kinerja dari infrastruktur terbangun dalam mendukung keberlanjutan fungsi yang ada. Hal ini merupakan titik lemah pengelolaan aset jika dipandang sebagai aset negara. Pengelolaan aset infratruktur membutuhkan keseriusan dimana siklusnya dimulai dari tahapan ide/gagasan, perencanaan, pengadaan asset, operasi dan pemeliharaan asset, dan penghapusan asset (Bria, 2017).

Maksud kegiatan ini adalah untuk mengidentifikasi kondisi eksisting bangunan embung sedangkan tujuan dari kegiatan pengabdian kepada masyarakat ini adalah tersusunnya suatu kajian terhadap hasil identifikasi kerusakan dan rekomendasi perbaikan embung kecil. Sasaran kegiatan ini adalah pengumpulan data-data teknis embung yang berada di wilayah kota Kupang, melihat kondisi bangunan dan menganalisa fungsi layanan maupun outcome dari embung tersebut.

\section{METODE PELAKSANAAN}

\section{Jenis dan Sumber Data}

Prinsip pelaksanaan kegiatan ini mengacu kepada standar yang telah dikeluarkan oleh Dirjen Sumber Daya Air (Dirjen SDA). Jenis data untuk kebutuhan penyusunan data embung kecil meliputi data primer dan sekunder. Data primer diperoleh langsung dari hasil pengamatan di lapangan sedangkan data sekunder diperoleh dari instansi terkait, literatur dan studi terdahulu. Data sekunder yang dibutuhkan adalah data pembangunan embung kecil dari tahun 2008-2017, peta administrasi kabupaten, kecamatan dan kelurahan/desa (PT. Kencana Adya Daniswara, 2018).
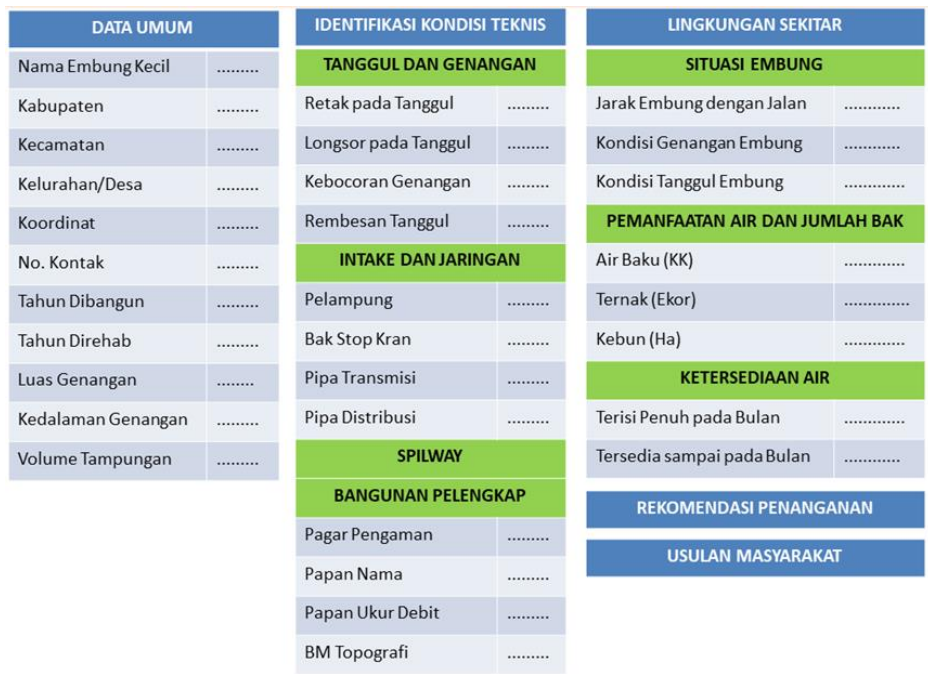

Gambar 1. Blanko Survei Identifikasi Embung Kecil di Kota Kupang 


\section{Proses Pengumpulan Data}

Teknik pengumpulan data dilakukan secara partisipatif melalui survei ke lapangan, observasi dan wawancara dengan masyarakat di sekitar lokasi embung serta direksi teknik bidang OP SDA dan Irigasi Dinas PUPR Provinsi NTT.

\section{Sosialisasi dan Pengumpulan Data Lapangan}

Pada tahap awal dilakukan sosialisasi untuk memberikan penjelasan kepada masyarakat tentang studi ini untuk mendapat masukan tentang berbagai hal yang menyangkut dengan permasalahan yang ada di wilayah embung tersebut. Setelah itu dilakukan pengumpulan data baik data teknis maupun data umum tentang kondisi jaringan embung, kerusakan yang tejadi maupun kondisi banjir yang pernah terjadi pada daerah embung tersebut. Hal ini sangat penting untuk dapat dilakukan survei dan pengukuran lanjutan di lapangan.

\section{Dokumentasi Lapangan/Foto-foto Lapangan}

Dokumentasi lapangan/foto-foto lapangan sangat membantu agar dapat memperkirakan dan mengevaluasi kondisi riil secara visualisasi dari suatu kondisi teknis embung kecil dan lingkungan sekitar agar dapat membantu dalam pangambilan keputusan guna perencanaan teknis maupun pelaksanaan operasi dan pemeliharaan jaringan irigasi sehingga dapat bermanfaat secara optimal sesuai dengan tujuan dan sasaran dikemudian hari.

\section{Identifikasi Kerusakan Bangunan dan Jaringan}

Pekerjaan identifikasi kerusakan pada bangunan utama dan pelengkap embung kecil dan jaringannya dilakukan agar dapat diketahui permasalahannya/kerusakan yang terjadi. Tahap inventarisasi dimaksudkan untuk mendapatkan data teknis dan kondisi fisik dari bangunan-bangunan embung. Pelaksanaan pekerjaan tersebut berupa survei langsung untuk mendapatkan data di lapangan dengan menggunakan format isian yang telah disiapkan. Adapun inventarisasi dilakukan untuk daerah embung kecil, dilengkapi dengan foto-foto bangunan beserta skema jaringannya.

\section{Rangkuman dan Rekomendasi Penanganan Kerusakan}

Kompilasi dan evaluasi hasil inventarisasi merupakan data hasil observasi lapangan dan data sekunder serta matriks kerusakan yang terjadi pada embung yang selanjutnya akan dijadikan data base embung kecil dan peta sebarannya.

\section{Dokumentasi Kerusakan}

Dokumentasi kerusakan bangunan digunakan sebagai arsip untuk mengevaluasi dan mengidentifikasi kerusakan bangunan. Kegiatan ini dapat dilakukan dengan menggunakan kamera foto. Cara tersebut digunakan sebagai data yang dapat mereview kembali kegiatan survei, sehingga kondisi lapangan dapat diidentifikasi lebih detail.

\section{HASIL DAN PEMBAHASAN}

\section{Diskusi dan Presentasi Pendahuluan}

Pada tahap ini telah dilakukan diskusi pendahuluan dan dipresentasikan kepada pejabat dan direksi teknis bidang OP SDA Dinas PUPR Provinsi NTT terkait hal-hal yang 
dipersiapkan sebelum melakukan survei lapangan. Pada tahap ini juga telah disepakati metode kerja, analisis dan output yang akan dihasilkan dari kegiatan pengabdian masyarakat ini.

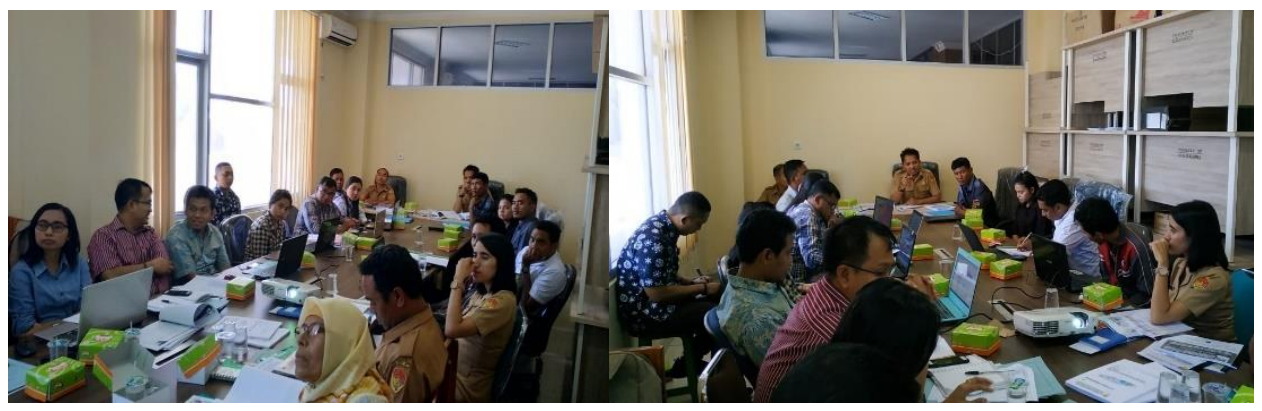

Gambar 2. Diskusi dan Presentasi Pendahuluan

\section{Hasil Identifikasi Kerusakan Embung Kecil}

Embung kecil di Kota Kupang yang merupakan aset Dinas Pekerjaan Umum dan Penataan Ruang Provinsi Nusa Tenggara Timur berjumlah 4 embung yang tersebar di 1 Kecamatan. Survei lapangan dilakukan pada tiap-tiap embung untuk mendapatkan kondisi eksisting embung pada saat ini. Embung kecil yang merupakan aset Dinas PUPR Provinsi NTT selengkapnya dapat dilihat pada Tabel 1.

Tabel 1. Embung Kecil di Kota Kupang

\begin{tabular}{lllllll}
\hline No. & Embung Kecil & Kecamatan & Kelurahan/Desa & RT, RW & Bujur & Lintang \\
\hline 1 & Fatung & Alak & Naioni & RT 021, RW 010 & 567417.5 & 8863995 \\
\hline 2 & Kuaputu & Alak & Manulai II & RT 018, RW 007 & 561763.8 & 8870263 \\
\hline 3 & Kiutunis & Alak & Manulai II & RT 001, RW 001 & 562739.3 & 8872136 \\
\hline 4 & Oetalu & Alak & Naioni & RT 019, RW 009 & 566321.2 & 8864447 \\
\hline
\end{tabular}

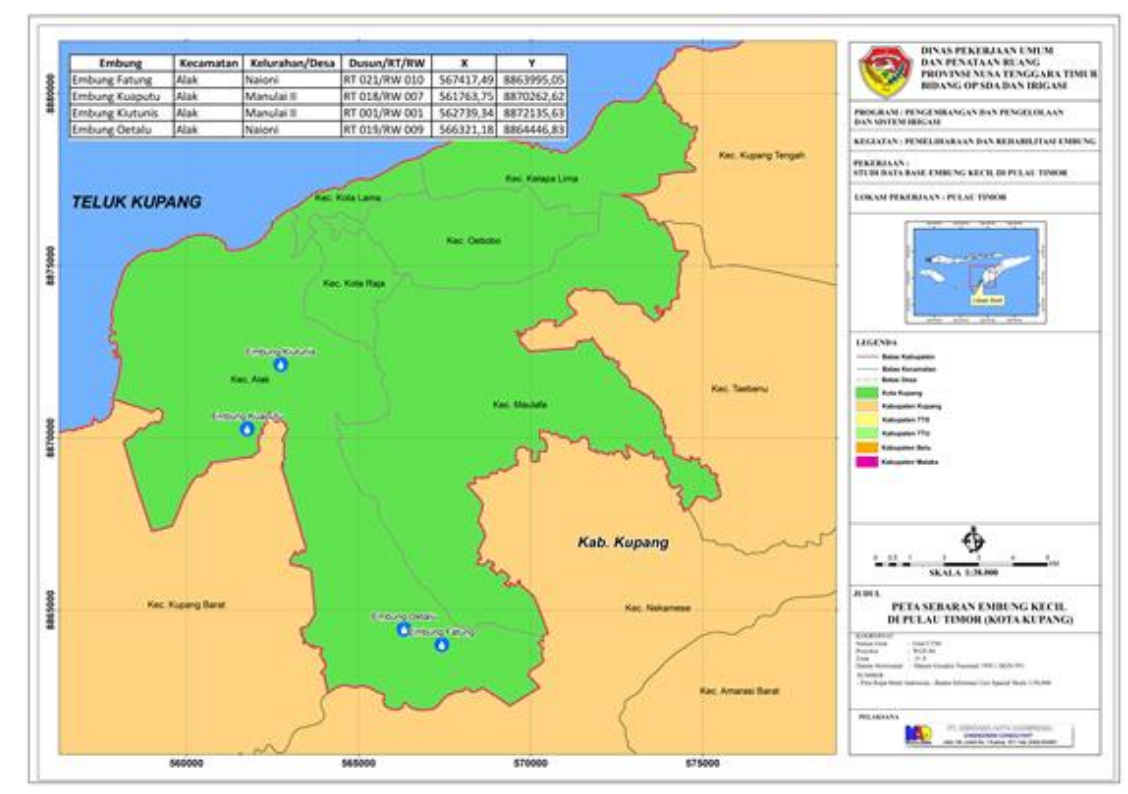

Gambar 3. Peta Sebaran Embung Kecil di Kota Kupang 
Berikut ditampilkan tipe bangunan, lokasi dan dokumentasi kerusakan setiap embung kecil di kota Kupang.

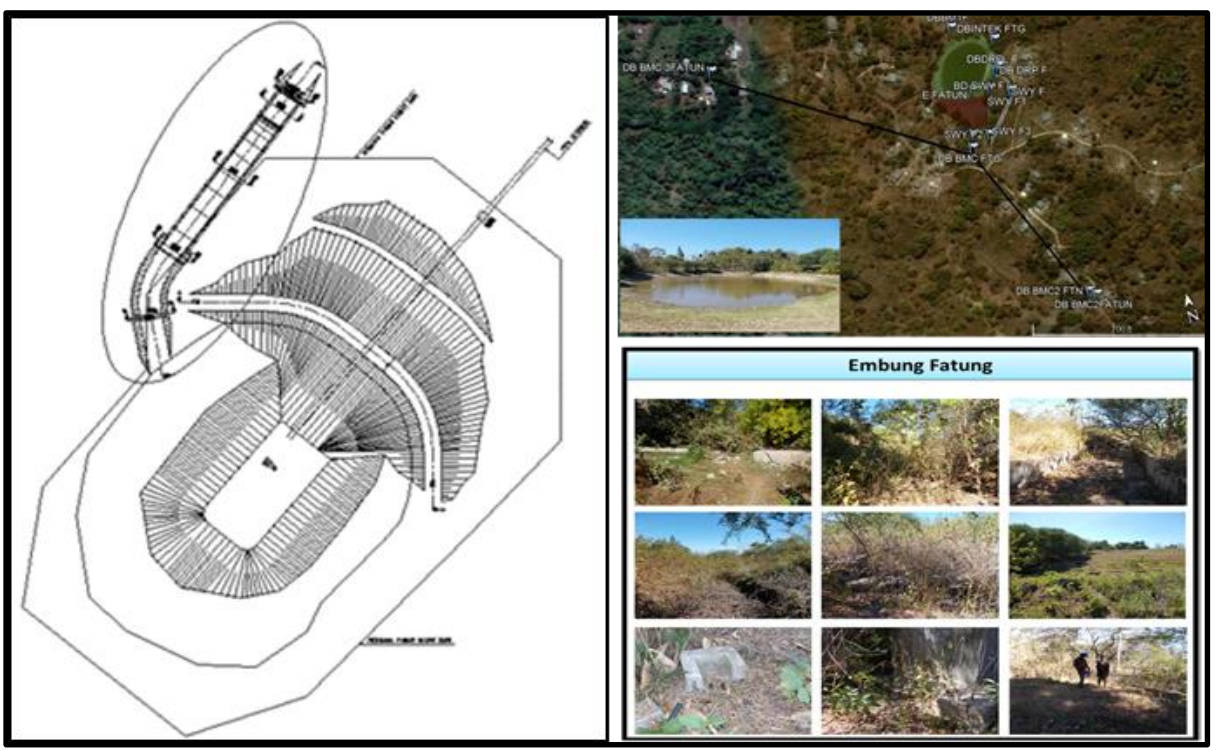

Gambar 4. Embung Fatung

Tabel 2. Hasil Identifikasi Kerusakan Embung Fatung

\begin{tabular}{|c|c|}
\hline Identifikasi Kondisi Teknis & Kondisi Lingkungan Sekitar \\
\hline Kondisi Tanggul dan Genangan & Situasi Embung \\
\hline Retak pada Tanggul :- & Jarak Embung $: \pm 75 \mathrm{~m}$ dari jalan \\
\hline Longsor pada Tanggul : - & Kondisi Genangan: Air terisi \\
\hline Kebocoran Genangan : :- & Kondisi Tanggul: Rendah jadi pada \\
\hline Rembesan Tanggul :- & $\begin{array}{l}\text { musim hujan air melimpas melalui } \\
\text { bagian atas tanggul }\end{array}$ \\
\hline \multicolumn{2}{|l|}{ Kondisi Intake dan Jaringan } \\
\hline & Pemanfaatan Air Embung \\
\hline : Tidak Ada & Manusia: \pm 30 KK (3 Buah Bak Manusia, \\
\hline Bak Stop Kran & Kondisi rusak/tidak berfungsi) \\
\hline Pipa Transmisi & Ternak : \pm 50 Ekor (3 Buah Bak Hewan, \\
\hline Pipa Distribusi & $\begin{array}{l}\text { Kondisi rusak/tidak berfungsi) } \\
\text { Kebun : } \pm 5 \mathrm{Ha}\end{array}$ \\
\hline \multicolumn{2}{|l|}{ Kondisi Spilway } \\
\hline \multirow{3}{*}{$\begin{array}{l}\text { Drempel rusak, ditumbuhi semak } \\
\text { Ujung Spilway rusak }\end{array}$} & Ketersediaan Air Embung \\
\hline & Terisi penuh pada bulan Januari \\
\hline & Tersedia sampai pada bulan Oktober \\
\hline \\
\hline \multicolumn{2}{|l|}{ Pagar Pengaman : Tidak ada } \\
\hline Papan Nama & \\
\hline : Tidak ada & \\
\hline BM Topografi & \\
\hline
\end{tabular}




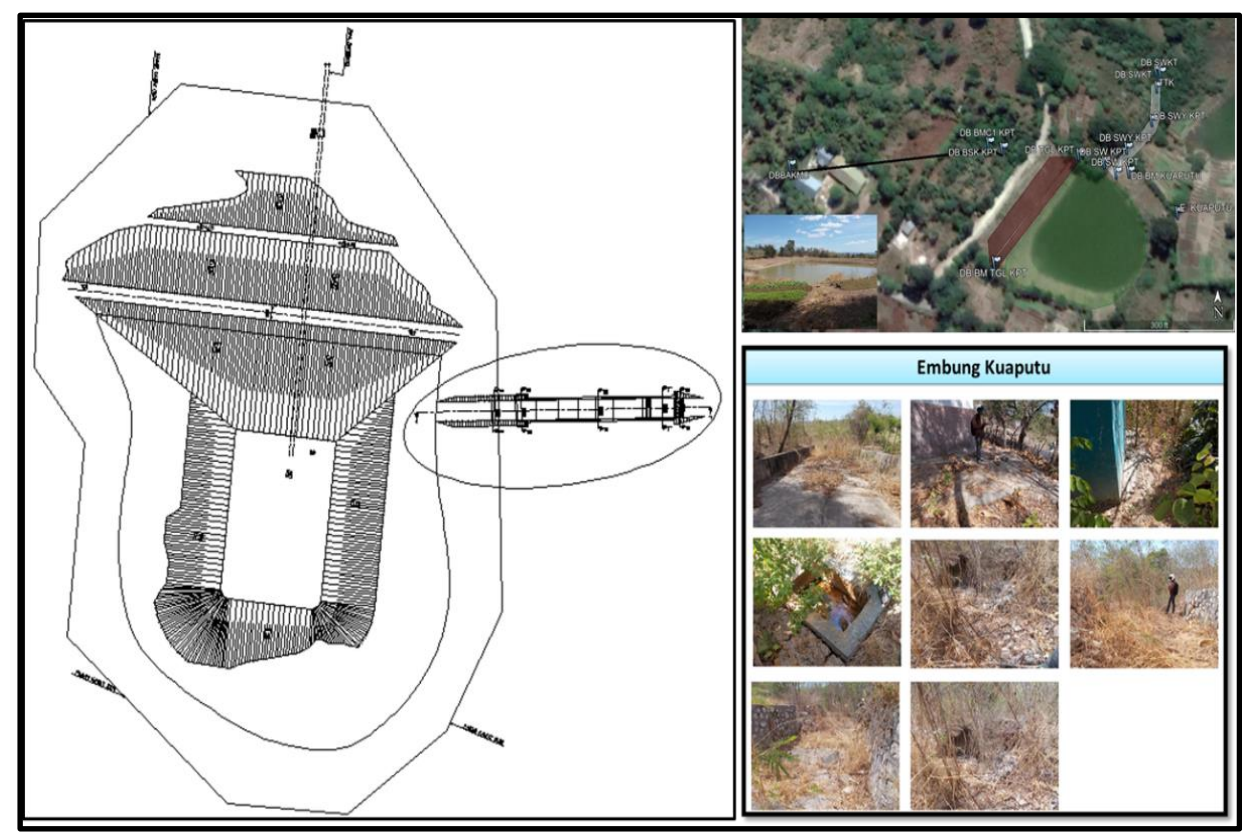

Gambar 5. Embung Kuaputu

Tabel 3. Hasil Identifikasi Kerusakan Embung Kuaputu

\begin{tabular}{|c|c|c|}
\hline \multicolumn{2}{|c|}{ Identifikasi Kondisi Teknis } & Kondisi Lingkungan Sekitar \\
\hline \multicolumn{2}{|c|}{ Kondisi Tanggul dan Genangan } & Situasi Embung \\
\hline \multicolumn{2}{|c|}{ Retak pada Tanggul :- } & Jarak Embung $: \pm 25 \mathrm{~m}$ dari jalan \\
\hline \multicolumn{2}{|c|}{ Longsor pada Tanggul : - } & Kondisi Genangan: Air terisi \\
\hline \multicolumn{2}{|c|}{ Kebocoran Genangan : - } & Kondisi Tanggul: bersih \\
\hline \multicolumn{2}{|l|}{ Rembesan Tanggul } & \\
\hline \multicolumn{2}{|c|}{ Kondisi Intake dan Jaringan } & $\begin{array}{l}\text { Pemanfaatan Air Embung } \\
\text { Manusia: } \pm 40 \text { KK ( } 2 \text { Buah Bak Manusia, } \\
\text { Kondisi rusak/tidak berfungsi) }\end{array}$ \\
\hline Pelampung & : Tidak Ada & Ternak $: \pm 70$ Ekor \\
\hline Bak Stop Kran & : Ada (rusak) & Kebun $: \pm 1$ Ha (mesin pompa air) \\
\hline Pipa Transmisi & : Ada (rusak) & \\
\hline Pipa Distribusi & : Ada (rusak) & $\begin{array}{l}\text { Ketersediaan Air Embung } \\
\text { Terisi penuh pada bulan Februari }\end{array}$ \\
\hline \multicolumn{3}{|l|}{ Ditumbuhi semak } \\
\hline \multicolumn{3}{|c|}{ Kondisi Bangunan Pelengkap } \\
\hline Pagar Pengaman : & Tidak ada & \\
\hline Papan Nama : & Tidak ada & \\
\hline Peil Scale & Tidak ada & \\
\hline BM Topografi : & 2 buah & \\
\hline
\end{tabular}




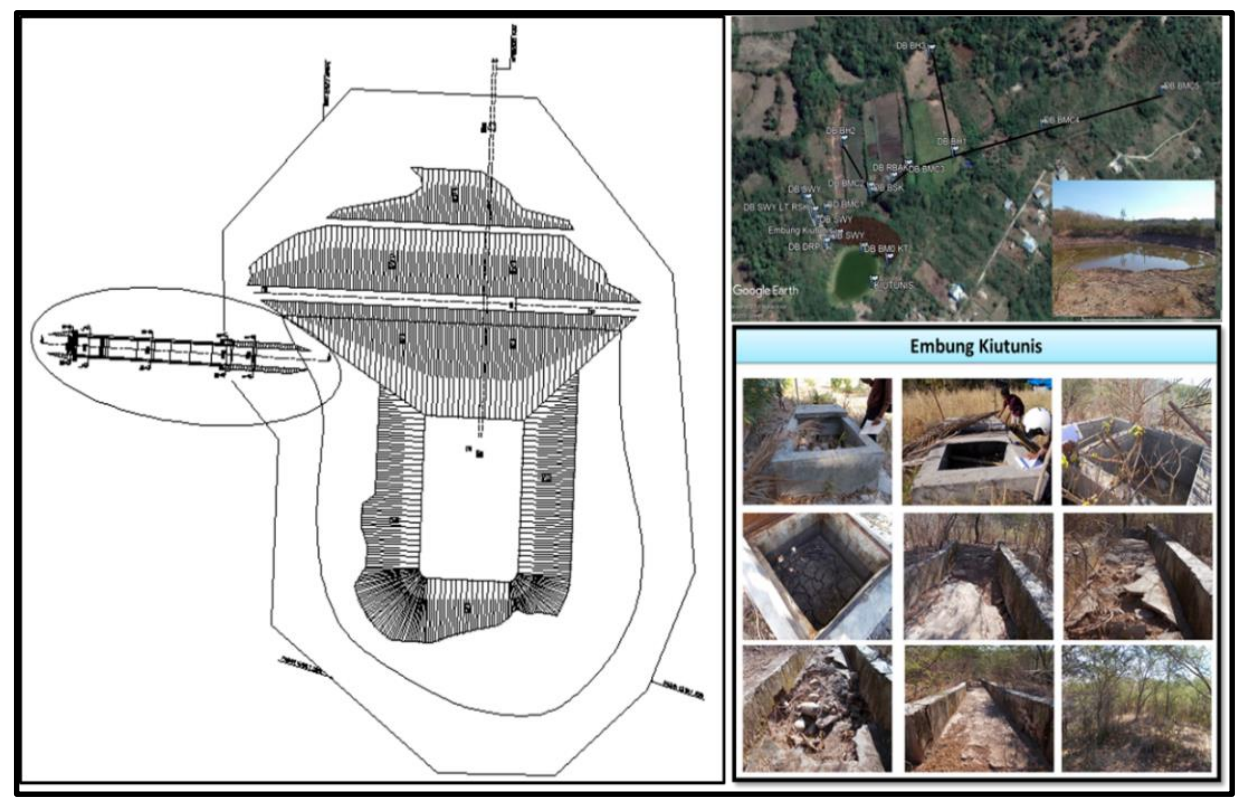

Gambar 6. Embung Kiutunis

Tabel 4. Hasil Identifikasi Kerusakan Embung Kiutunis

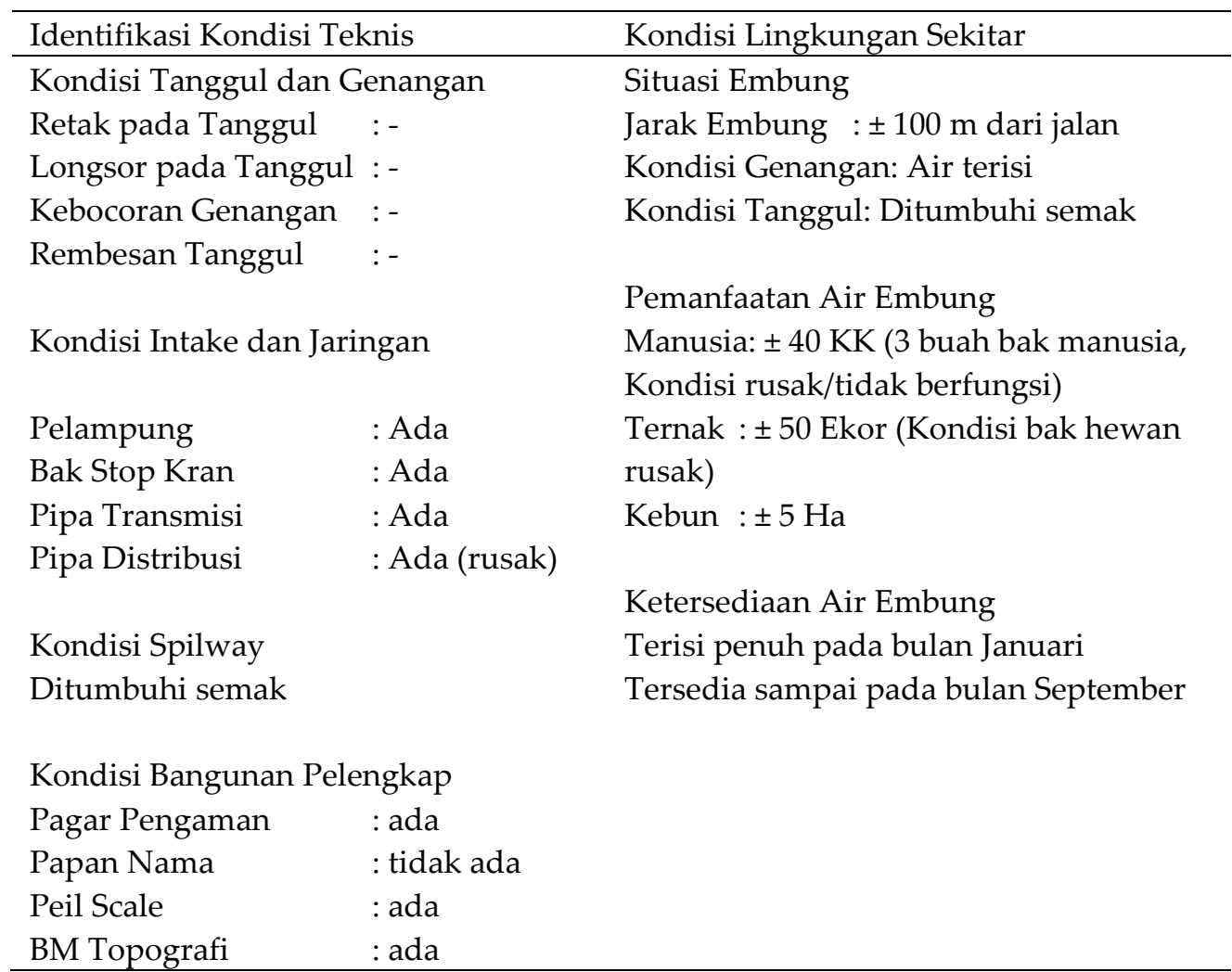



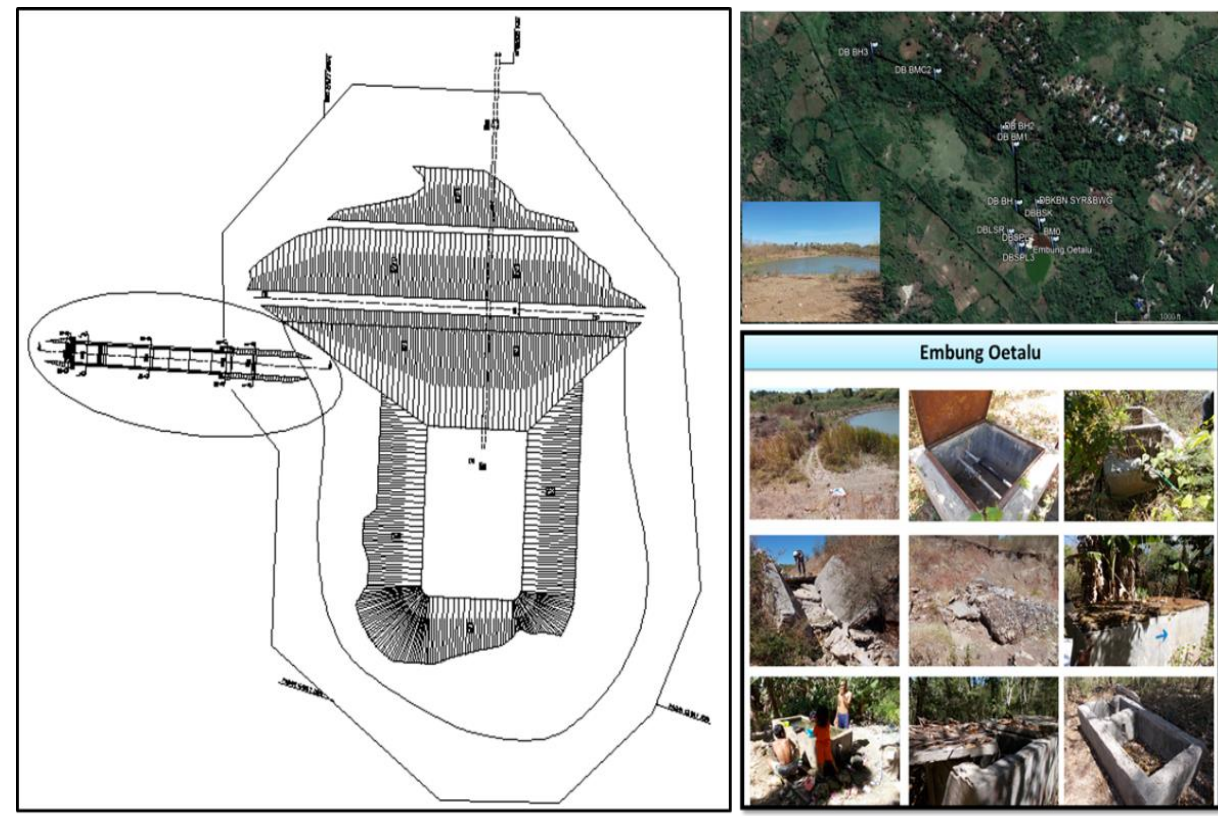

Gambar 7. Embung Oetalu

Tabel 5. Hasil Identifikasi Kerusakan Embung Oetalu

\begin{tabular}{|c|c|c|}
\hline \multicolumn{2}{|c|}{ Identifikasi Kondisi Teknis } & Kondisi Lingkungan Sekitar \\
\hline \multicolumn{2}{|c|}{ Kondisi Tanggul dan Genangan } & Situasi Embung \\
\hline \multicolumn{2}{|c|}{ Retak pada Tanggul :- } & Jarak Embung $: \pm 250 \mathrm{~m}$ dari jalan \\
\hline \multicolumn{2}{|c|}{ Longsor pada Tanggul : - } & Kondisi Genangan: Air terisi \\
\hline \multicolumn{2}{|c|}{ Kebocoran Genangan : - } & Kondisi Tanggul: Ditumbuhi semak \\
\hline \multicolumn{2}{|l|}{ Rembesan Tanggul } & \\
\hline \multicolumn{2}{|c|}{ Kondisi Intake dan Jaringan } & $\begin{array}{l}\text { Pemanfaatan Air Embung } \\
\text { Manusia: } \pm 30 \text { KK ( } 2 \text { buah bak manusia, } \\
\text { Kondisi rusak/tidak berfungsi) }\end{array}$ \\
\hline Pelampung & : Tidak Ada & Ternak $: \pm 50$ Ekor ( 3 buah bak hewan \\
\hline Bak Stop Kran & : Ada & dengan kondisi rusak) \\
\hline Pipa Transmisi & : Ada & Kebun : $\pm 5 \mathrm{Ha}$ \\
\hline \multicolumn{3}{|c|}{ Pipa Distribusi $\quad$ : Ada (rusak) } \\
\hline \multirow{2}{*}{\multicolumn{2}{|c|}{ Kondisi Spilway }} & Ketersediaan Air Embung \\
\hline & & Terisi penuh pada bulan November \\
\hline \multicolumn{2}{|l|}{ Ditumbuhi semak } & Tersedia sampai pada bulan Oktober \\
\hline \multicolumn{3}{|c|}{ Drempel tertimbun endapan } \\
\hline \multicolumn{3}{|c|}{ Ujung Spilway patah akibat longsor } \\
\hline \multicolumn{3}{|c|}{ Kondisi Bangunan Pelengkap } \\
\hline \\
\hline \multicolumn{3}{|c|}{$\begin{array}{l}\text { Pagar Pengaman : tidak ada } \\
\text { Papan Nama } \quad \text { tidak ada }\end{array}$} \\
\hline \multicolumn{3}{|l|}{ Peil Scale $\quad$ : ada } \\
\hline BM Topografi : ada & & \\
\hline
\end{tabular}




\section{Usulan Rekomendasi Perbaikan Embung Kecil di Kota Kupang}

Berdasarkan hasil identifikasi kerusakan pada embung kecil yang diperoleh dari hasil survei lapangan maka usulan perbaikan dari masyarakat sekitar Embung yang menjadi rekomendasi dari kegiatan pengabdian pada masyarakat ini ditampilkan pada Tabel 6.

Tabel 6. Rekomendasi Perbaikan Embung Kecil di Kota Kupang

\begin{tabular}{lll}
\hline No. & Embung Kecil & Rekomendasi Perbaikan dan Usulan \\
\hline 1 & Fatung & Perbaikan pagar pengaman embung; \\
& & Pembersihan semak dan pohon di areal embung; \\
& & Perbaikan distribusi jaringan perpipaan; \\
& Membangun kembali bak-bak embung dengan melihat \\
& kebutuhan masyarakat sekitar yaitu bak manusia dan \\
& kebun; \\
& Memperbaiki tanggul. \\
\hline 2 & Kuaputu & Perbaikan pagar pengaman embung; \\
& Perbaikan distribusi jaringan perpipaan; \\
& Membangun kembali bak-bak embung dengan melihat \\
& kebutuhan masyarakat sekitar yaitu bak manusia dan \\
& kebun. \\
\hline 3 & Kerbaikan pagar pengaman embung; \\
& Pembersihan semak dan pohon di areal embung; \\
& Perbaikan distribusi jaringan perpipaan; \\
& Membangun kembali bak-bak embung dengan melihat \\
& kebutuhan masyarakat sekitar yaitu bak manusia dan \\
& kebun. \\
\hline 4 & Perbaikan pagar pengaman embung; \\
& Pembersihan semak dan pohon di areal embung; \\
& Perbaikan distribusi jaringan perpipaan; \\
& Membangun kembali bak-bak embung dengan melihat \\
& kebutuhan masyarakat sekitar yaitu bak manusia dan \\
& kebun. \\
\hline &
\end{tabular}

Embung-embung tersebut sangat bermanfaat untuk masyarakat sekitar karena merupakan penampung air yang berfungsi untuk irigasi, air baku, ternak dan lain-lain. Akan tetapi, pemerintah tidak mungkin membangun semua embung tersebut karena masalah keterbatasan finansial, sehingga pemerintah harus menentukan prioritas perbaikan jangka pendek dari embung-embung tersebut (Sutapa, 2010; Anjasmoro et.al, 2015; Nirwana, 2016). Selain itu juga perlu dievaluasi kinerja penyediaan air baku untuk setiap embung dengan berbagai alternatif pendekatan salah satunya adalah Balanced Scorecard (Situmorang et.al, 2019).

\section{Diskusi dan Presentasi Akhir}

Dalam kegiatan ini telah dipaparkan hasil kegiatan yang sudah dilaksanakan yang termuat dalam laporan akhir diantaranya adalah bagian studi pendahuluan, hasil 
identifikasi kerusakan embung dalam bentuk matriks identifikasi, rekomendasi perbaikan embung kecil dan peta sebaran embung kecil di kota Kupang.

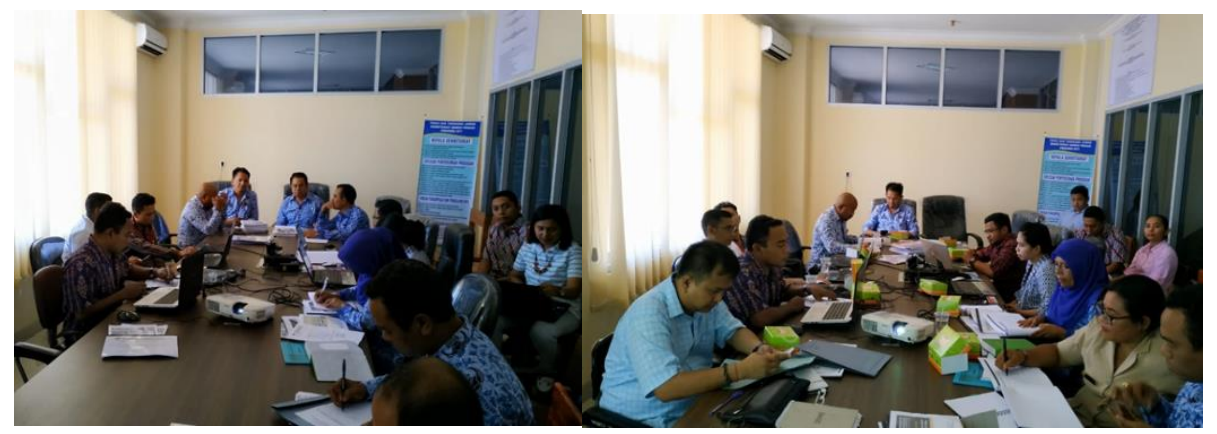

Gambar 7. Diskusi dan Presentasi Akhir

Berdasarkan hasil diskusi dan presentasi ini, telah disepakati bahwa output hasil kegiatan pelaksanaan pengabdian pada masyarakat tentang identifikasi kerusakan dan rekomendasi perbaikan untuk embung kecil di kota Kupang sudah sesuai dengan kriteria yang diharapkan dan layak untuk ditindaklanjuti.

\section{SIMPULAN}

Kegiatan pengabdian kepada masyarakat yang dilaksanakan di Kota Kupang telah berhasil mencapai tujuannya. Hal ini terlihat dari hasil survey identifikasi dan analisis kerusakan pada setiap embung kecil yang telah didiskusikan, dipresentasikan dan disetujui oleh Dinas Perumahan Rakyat dan Penataan Ruang Bidang OP SDA dan Irigasi Provinsi Nusa Tenggara Timur. Berdasarkan hasil identifikasi ini telah dibuat suatu rekomendasi perbaikan untuk setiap kerusakan pada embung kecil di Kota Kupang. Selain itu, output dari kegiatan pengabdian kepada masyarakat ini adalah satu buah artikel ilmiah yang akan diterbitkan pada jurnal pengabdian kepada masyarakat.

Hasil rekomendasi perbaikan yang diusulkan pada setiap embung kecil di Kota Kupang hendaknya perlu ditindaklanjuti oleh Dinas Perumahan Rakyat dan Penataan Ruang Bidang OP SDA dan Irigasi Provinsi Nusa Tenggara Timur karena kebutuhan air untuk masyarakat di sekitar embung yang sangat mendesak.

\section{UCAPAN TERIMA KASIH}

Ucapan terima kasih diberikan kepada PT. Kencana Adya Daniswara dan Dinas Perumahan Rakyat dan Penataan Ruang Bidang OP SDA dan Irigasi Provinsi Nusa Tenggara Timur atas kerjasamanya dalam keberhasilan kegiatan pengabdian kepada masyarakat ini.

\section{REFERENSI}

Anjasmoro, B., Suharyanto, \& Sangkawati, S. (2016). Analisis prioritas pembangunan embung metode cluster analysis, AHP dan weighted average (Studi kasus: Embung di Kabupaten Semarang). Media Komunikasi Teknik Sipil, 21(2), 101-112. 
Asdak, C. (1995). Hidrologi dan pengelolaan daerah aliran sungai. Yogyakarta: Gadjah Mada University Press.'

Badan Pusat Statistik Kota Kupang. (2018). Kota Kupang dalam angka 2018. Kupang: Badan Pusat Statistik.

Bria, M. (2017). Analisis kriteria untuk perencanaan program pemeliharaan embung irigasi (Studi Kasus: Embung Haliwen dan Haekrit Kabupaten Belu). Jurnal Teknik Sipil dan Perencanaan, 19(2), 83-89.

Hanggara, A. I., \& Irvani, H. (2019). Analisa kelayakan teknis dan ekonomi embung Putukrejo Kabupaten Malang. Reka Buana: Jurnal Ilmiah Teknik Sipil dan Teknik Kimia, $4(1), 30-38$.

Kasiro, I. (1994). Pedoman kriteria desain embung kecil untuk daerah semi kering di Indonesia. Jakarta: Direktorat Jenderal Pengairan Departemen Pekerjaan Umum.

Nirwana, P. M. (2016). Penyusunan prioritas rehabilitasi embung di Kabupaten Malang Provinsi Jawa Timur. (Unpublished master's thesis) Institut Teknologi Sepuluh November, Surabaya, Indonesia.

Notoatmojo, B., \& Rivai, R. (2001). Optimasi pengembangan embung di Indonesia. Journal The Winners, 2(1), 12-17.

PT. Kencana Adya Daniswara. (2018). Laporan akhir studi database embung kecil di Pulau Timor. Kupang: Dinas PUPR Provinsi NTT.

Situmorang, W., Anwar, N., \& Sidharti, T. S. (2019). Evaluasi kinerja penyediaan air baku embung sei gesek dengan pendekatan balanced scorecard. Jurnal Manajemen Teori dan Terapan, 12(1), 18-29.

Subarkah, I. (1990). Hidrologi untuk perencanaan bangunan air. Bandung: Ide Dharma.

Sutapa, I. W. (2008). Studi potensi embung sub wilayah sungai watutela wuno di wilayah kota Palu dan Kabupaten Donggala Sulawesi Tengah. MEKTEK, 10(1), 61-68.

Sutapa, I. W. (2010). Studi Inventarisasi potensi embung wilayah sungai Parigi Poso. SMARTek, 8(4), 241-250. 